\title{
Translating Evidence into Practice: Insights on the Reporting of Trial Results to Health Professionals and Institutions
}

\section{Aplicação da Evidência à Prática Clínica: Estratégias para a Comunicação dos Resultados de Ensaios Clínicos a Profissionais e Instituições de Saúde}

\author{
João FIRMINO-MACHADO $\rrbracket^{1,2}$, Romeu MENDES ${ }^{1,3}$, Amélia MOREIRA ${ }^{2}$, Nuno LUNET 1,4 \\ Acta Med Port 2019 Nov;32(11):683-685 - https://doi.org/10.20344/amp.11593
}

\begin{abstract}
Keywords: Evidence-Based Practice; Information Dissemination; Mass Screening; Randomized Controlled Trial; Translational Medical Research

Palavras-chave: Disseminação da Informação; Ensaio Clínico Controlado Randomizado; Investigação Médica Translacional; Prática Clínica Baseada em Evidências; Programas de Rastreio
\end{abstract}

\section{INTRODUCTION}

The communication of results from public health interventions to the professionals involved in their implementation and evaluation is an important component of research in this field, and is essential to have the support of health professionals who will be involved in their implementation and evaluation. ${ }^{1}$ In addition to academic publications and presentations in scientific events, this requires the communication of results using multiple means, to reach different targets, including easy-to-read reports directed to broad audiences. ${ }^{2}$

Some strategies that promote an effective communication of results have been described, such as tailoring the message to include information that is specific for each individual/institution or selecting the most relevant results for each audience segment. ${ }^{3}$

\section{PROPOSED FRAMEWORK}

Here we propose a framework to report the main findings of experimental studies to health institutions and professionals involved in the assessment of the effectiveness of an intervention, based on the trial Stepwise Strategy to Improve Cervical Cancer Screening Adherence (SCANCervical Cancer), which was previously described in detail elsewhere. ${ }^{4,5}$ This study tested the invitation to cervical cancer screening through automated and personalized text messages, phone calls and reminders to increase the adherence to cervical cancer screening, in relation to the standard of care (written letter). The participants were women eligible for cervical cancer screening, aged 25 to 49 years, registered at one of the 13 participant primary care units, including urban and rural areas (Fig. 1 of the Appendix), with an available mobile phone registered at the
National Health Service database. The primary outcome was the adherence to screening 45 days after implementing the interventions.

We produced a two-page template (please see Appendix) to disseminate the evidence produced by a pragmatic randomized controlled trial to the involved health professionals and institutions. It includes the description of the study rationale, design of the trial, settings and participants, interventions, results of the study, discussion of the internal and external validity, summary of main findings, as well as funding and conflict of interest. Here is a detailed analysis of each section:

Proposed template to communicate the main findings of experimental studies

\section{Rationale for the investigation}

Identification, magnitude and relevance of the problem to be tackled with the intervention. This section should also identify the knowledge gaps addressed by the study.

\section{Study description}

\section{1 - Objective and study design}

Objective of the study and study design details, such as number of centres, randomization units, blinding and other methodological features with potential impact on internal and external validity.

\section{2 - Settings and participants}

Inclusion and exclusion criteria, as well as the characteristics of the areas/institutions involved in the study. This information can be communicated using plain text, but also graphical representations, such as flowcharts or diagrams (e.g., CONSORT diagram). Maps can also be used to

1. EPIUnit. Instituto de Saúde Pública. Universidade do Porto. Porto. Portugal.

2. Unidade de Saúde Pública. Agrupamento de Centros de Saúde do Porto Ocidental. Porto. Portugal.

3. Unidade de Saúde Pública. Agrupamento de Centros de Saúde do Marão e Douro Norte. Vila Real. Portugal.

4. Departamento de Ciências da Saúde Pública e Forenses e Educação Médica. Faculdade de Medicina. Universidade do Porto. Porto. Portugal.

$\triangle$ Autor correspondente: João Firmino-Machado. firmino.firminomachado@gmail.com

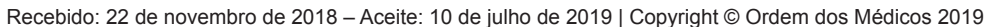


depict the geographical distribution of the recruiting sites (e.g., Fig. 1 of the appendix). ${ }^{6}$

\section{3 - Tested intervention and control}

Tested intervention and comparator, and study implementation. Flowcharts, process content diagrams or swim lane activity diagrams may be useful to improve the understanding of complex study interventions. ${ }^{7}$ These graphical elements may be particularly useful when the study designs are complex (e.g., Fig. 2 of the Appendix).

\section{Results of the trial}

\section{1 - Overall effect of the intervention.}

Overall results of the intervention can be presented using different effect measures, along with precision estimates (e.g., 95\% confidence intervals), and $p$-values for comparisons between intervention and control groups.

Measures such as the number needed to treat (NNT), as these are easily interpreted by clinicians and illustrate the number of patients that need to be treated to prevent one adverse outcome. NNT can also be adapted to address different research topics, namely vaccination (number needed to vaccinate) or screening (number needed to screen).

3.2 - Effect of the intervention by recruiting site and population subgroups.

Effect estimates stratified by recruiting sites, for benchmarking of results.

Funnel or forest plots may be used to depict strata-specific results. Funnel plots are commonly used to access publication bias in meta-analyses, but they can also be used to depict the heterogeneity of effect measures across study centres. ${ }^{8}$

This format of graphic display of the results avoids the use of confidence intervals, though instructions for a proper interpretation of the funnel plots may be needed (e.g., Fig. 3 of the Appendix). Forest plots could be used instead, for graphical presentation of centre-specific data, as well as to depict the effect of the intervention stratified by any relevant baseline characteristic, namely sociodemographic variables or presence of comorbidities (e.g., Fig. 4 of the Appendix), enabling the identification of participant subgroup(s) in which the intervention is more/less beneficial.

\section{Internal and external validity}

\section{1 - Internal validity}

Threats to the internal validity of the study should be addressed in this section and may comprise topics such as imbalance of participants baseline characteristics between intervention and control groups, contamination, differential losses to follow-up or misclassification of the outcome, among others.

\section{2 - External validity}

Limits to the generalizability of study findings, i.e. "the degree to which results of a study may apply, be generalized, or be transported to populations or groups that did not participate in the study", ${ }^{9}$ along with the extent to which the trial may be considered pragmatic should be addressed.
A more comprehensive and systematic assessment of the pragmatic nature of the trial may be achieved using tools such as the PRagmatic Explanatory Continuum Indicator Summary 2 (PRECIS-2). ${ }^{10}$

\section{Summary of main findings}

The summary of the main findings may be complemented by a statement on the potential applicability or usefulness of the intervention in the specific setting being targeted by the report.

\section{Funding and conflict of interest}

All project grants or supporting funds of the research project should be presented, so as any conflict of interest of the research team, as defined by the International Committee of Medical Journal Editors (ICMJE).

\section{USE OF THE PROPOSED TEMPLATE IN SCAN TRIAL}

A personalized report was assembled for each primary care unit involved in the trial, using the proposed template. Each document was signed by the principal investigator and sent by e-mail to all the involved health professionals and institutions. The use of a two-page report allowed health professionals to quickly read it but also to print and post it as poster in each primary care unit, promoting the dissemination of findings.

A meeting with the primary care unit was scheduled to discuss the overall results of the trial, but also the effect of the intervention in each recruiting site. The same presentation was conducted with the coordinators of the primary care units involved.

Through these strategies we have promoted the discussion and dissemination of the study results to the involved health professionals and possibly contributed to a sustainable implementation of the tested intervention.

In conclusion, this two-page template can be easily customized according to the intended audience. This work may be useful to disseminate study findings of experimental studies, although further research is needed to quantify the acceptance of the proposed template by different groups of health professionals (medical doctors, nurses, health managers) and types of institutions (primary health care units, hospitals), but also to determine which is the most effective strategy to disseminate findings of distinct nature.

\section{CONTRIBUTIONS OF AUTHORSHIP}

João Firmino-Machado and Nuno Lunet designed the study. João Firmino-Machado, Romeu Mendes and Amélia Moreira were responsible for enrolling primary care units, family doctors and clinical secretaries in the trial. João Firmino-Machado collected all the data necessary for data analysis. Nuno Lunet conducted the data analysis with inputs from João Firmino-Machado. The proposed template was produced by João Firmino-Machado and presented to primary care units health professionals and policy makers by João Firmino-Machado, Romeu Mendes and Amélia 
Moreira. The first version of the manuscript was drafted by João Firmino-Machado and edited by Nuno Lunet. All authors revised and approved the final version of the manuscript. The lead author affirms that the manuscript is honest, accurate, and transparent and is accountable for all the aspects of the work.

\section{CONFLICT OF INTERESTS}

All the authors declare that they have no competing interests.

\section{REFERENCES}

1. Peters DH, Tran NT, Adam T. Implementation research in health: a practical guide. Alliance for Health Policy and Systems Research. Geneve: World Health Organisation; 2013.

2. Brownson RC, Fielding JE, Green LW. Building capacity for evidencebased public health: Reconciling the pulls of practice and the push of research. Annu Rev Public Health. 2018;393:3.1-3.27.

3. McCormack L, Sheridan S, Lewis M, Boudewyns V, Melvin CL, Kistler C, et al. Communication and dissemination strategies to facilitate the use of health-related evidence. Rockville: Agency for Healthcare Research and Quality; 2013

4. Firmino-Machado J, Mendes R, Moreira A, Lunet N. Stepwise strategy to improve cervical cancer screening adherence (SCAN-CC) - automated text messages, phone calls and face-to-face interviews: protocol of a population-based randomized controlled trial. BMJ Open. 2017;7:1-8.

5. Firmino-Machado J, Vilela S, Mendes R, Moreira A, Lunet N. Stepwise strategy to improve cervical cancer screening adherence (SCAN-

\section{FUNDING SOURCES}

This an academic study, supported by the institutions to which authors are affiliated, but with no specific funding.

Cervical Cancer) - automated text messages, phone calls and reminders: population based randomized controlled trial. Prev Med. 2018;114:123-33.

6. Onwuegbuzie A, Dickinson W. Mixed methods analysis and information visualization: Graphical display for effective communication of research results. Qual Rep. 2008;13:204-25.

7. Jun GT, Ward J, Morris Z, Clarkson J. Health care process modelling : which method when ? Int J Qual Heal Care. 2009;21:214-24.

8. Ahmed H, Naik G, Willoughby $\mathrm{H}$, Edwards AG. Communicating risk. BMJ. 2012;344:40-4.

9. Porta M. A dictionary of epidemiology. 6th ed. Oxford: Oxford University Press; 2014.

10. Loudon K, Treweek S, Sullivan F, Donnan P, Thorpe KE, Zwarenstein M. The PRECIS-2 tool: designing trials that are fit for purpose. BMJ. 2015;350:1-11. 